\title{
Binder-free three-dimensional silicon/carbon nanowire networks for high performance lithium-ion battery anodes
}

\author{
Wei Wang ${ }^{\mathrm{a}}$, Miao Tian ${ }^{\mathrm{a}}$, Yujie Wei ${ }^{\mathrm{b}}$, Se-Hee Lee ${ }^{\mathrm{a}}$, \\ Yung-Cheng Lee ${ }^{a}$, Ronggui Yang ${ }^{a, *}$
}

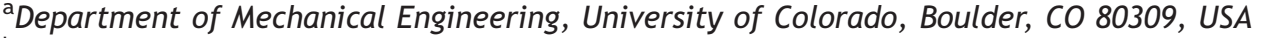

bState Key Laboratory of Nonlinear Mechanics, Institute of Mechanics, Chinese Academy of Sciences, Beijing 100190, PR China
\end{abstract}

Received 14 January 2013; received in revised form 12 March 2013; accepted 18 March 2013 Available online 27 March 2013

\section{KEYWORDS}

Nanowire network;

Si nanowires;

Lithium ion battery

\begin{abstract}
The three-dimensional (3-D) nano-architectures have attracted tremendous attention for applications in lithium-ion (Li-ion) batteries due to their unique structural advantages. In this work, we developed a facile approach to fabricate 3-D Silicon (Si) nanowire networks. By precipitation, Si nanowires spontaneously interwove with one another to form 3-D nanowire networks with large amount of micro/nano gaps, which can not only facilitate Li-ion transport but also effectively accommodate the volume change. Carbon coating was then applied on Si nanowire networks through a chemical vapor deposition (CVD) process, which not only mechanically strengthens the structure but also helps the formation of 3-D electrical conducting network. A Si/C nanowire network with a wire diameter of $75 \mathrm{~nm}$ and $12 \mathrm{wt} \%$ of carbon coating exhibits a very high specific capacity of $2300 \mathrm{mAh} \mathrm{g}^{-1}$ at a rate of $\mathrm{C} / 5$ and a high specific capacity of around $600 \mathrm{mAh} \mathrm{g} \mathrm{g}^{-1}$ at a high rate of $4.5 \mathrm{C}$. Our experimental investigations showed that the cycle life of such $\mathrm{Si} / \mathrm{C}$ nanowire network can be further prolonged by increasing the carbon coating content, decreasing the diameters of Si nanowires, or reducing the testing voltage window. A Si/C nanowire network with a wire diameter of $37 \mathrm{~nm}$ and $17 \mathrm{wt} \%$ carbon coating can retain $78 \%$ of the initial capacity after 60 cycles in a testing voltage window of $0.1-2 \mathrm{~V}$.

(c) 2013 Elsevier Ltd. All rights reserved.
\end{abstract}

*Corresponding author. Tel.: +1 303735 1003; fax: +1 3034923498.

E-mail address: ronggui.yang@colorado.edu (R. Yang).

\section{Introduction}

There are great demands for high-capacity and high-power lithium-ion (Li-ion) batteries for both portable electronics and electrical vehicles $[1,2]$. One of the key issues is to 
develop innovative battery materials and electrode structures [3]. Silicon ( $\mathrm{Si}$ ) has been broadly suggested to be a promising anode material for the next generation Li-ion batteries because of its highest theoretical capacity $\left(>3500 \mathrm{mAh} \mathrm{g}^{-1}\right)$, which is around 10 times higher than that of the commercial graphite anodes $\left(372 \mathrm{mAh} \mathrm{g}^{-1}\right)[4,5]$. However, the $-300 \%$ volume expansion in most Si-based electrodes during the charge/discharge process leads to their limited cycle life [6]. Micro/nanostructured Si electrodes has thus gained increasing attention due to the possibility in volume change accomodation [6,7]. A capacity of $>3500 \mathrm{mAh} \mathrm{g}^{-1}$ has been demonstrated in Si nanowire arrays [6]. Many different approaches have then been taken to improve the performance of one-dimensional Si nanostructures, such as $\mathrm{Si}$ nanotubes, $\mathrm{c}-\mathrm{Si} / \alpha-\mathrm{Si}$ and $\mathrm{C} / \mathrm{Si}$ core-shell nanowires [8-11]. However, the straight Si nanowire arrays are of unsatisfactory areal capacity with low mass loading density [8], where high-aspect ratio nanowire arrays would exhibit rapid performance degradation due to agglomeration and clustering of nanowires $[12,13]$.

On the other hand, three-dimensional (3-D) self-supported network structure could potentially eliminate the agglomeration problem, and hence improve the structural stability and the battery performance due to the interconnected electron transport network and the native gaps for lithium ion diffusion [12-14]. Benefiting from the 3-D network structure, ultra-fast battery with a charge/discharge rate of over $1000 \mathrm{C}$ was reported on a 3-D Ni/Li-Mn-O bicontinuous network[15], and significant enhancement of areal capacity and rate capability were also realized in 3-D Ni/ $\mathrm{TiO}_{2}$ and $\mathrm{Ni}$-Sn nanowire networks using porous anodized alumina (PAA) templated synthesis method $[12,13]$. Better rate capabilities and cycle lives have also been demonstrated in silicon nanostructures including 3-D interconnected Si nanowires, inverse-opal $\mathrm{Si}$ and $\mathrm{Ni} / \mathrm{Si}$ networks synthesized using silica sphere template-assisted chemical vapor deposition (CVD) or a modified CVD process [16-19].

In this work, we developed a facile and versatile process to fabricate the 3-D Si/C nanowire network using the ex-situ grown Si nanowires as building blocks, as shown in Fig. 1. The dispersed Si nanowires will entangle with each other during the precipitation process, and spontaneously interweave a 3-D nanowire network. On the basis of this unique structure, the kinetics process in Li-ion batteries can be potentially promoted, and consequently high capacity and the high-rate performance can be expected.

\section{Material and methods}

\section{Preparation of $\mathrm{Si} / \mathrm{C}$ nanowire network electrodes}

Si nanowires with average diameters of $75 \mathrm{~nm}$ and $37 \mathrm{~nm}$ were fabricated through metal-assisted wet-etching method using in-situ PAA templates as masks, where the details can be found in Ref. [20] and summarized in supporting information Section 1. As shown in Fig. 1, to fabricate the $\mathrm{Si} / \mathrm{C}$ nanowire networks, $25 \mathrm{mg}$ of Si nanowires were dispersed in $25 \mathrm{ml}$ ethanol solution by ultrasonicating for $10 \mathrm{~min}$ and then transferred into a box. After evaporating the ethanol solution in ambient environment for $5 \mathrm{~h}$, Si nanowires interwove with each other during the precipitation process and spontaneously formed a 3-D nano wire network. This nanowire precipitation process is rather universal and can be applied to abundant Si nanowires made through other processes [21-26]. The Si nanowire network was then coated with different thicknesses of carbon by decomposing ethylene through the CVD process for different durations of 2,4 , and $8 \mathrm{~h}$ at $700{ }^{\circ} \mathrm{C}$. To study the electrochemical properties of the as-obtained $\mathrm{Si} / \mathrm{C}$ nanowire networks, the electrodes for test were prepared by evaporating a $200 \mathrm{~nm}$ thick $\mathrm{Cu}$ film on the top of the $\mathrm{Si} / \mathrm{C}$ nanowire network as the current collector. The gravimetric capacities presented in this paper were calculated based on the weight of the whole electrode including the Si nanowires, the carbon coating, and the evaporated Cu current collector layer.

\section{Structural characterizations}

The field-emission scanning electron microscopy (FE-SEM, JEOL JSM-7401F) equipped with the energy dispersive spectroscopy (EDS) was employed to examine the morphologies and composition of the as-prepared nanowire networks, and the microstructure of dispersed nanowires was studied using a transmission electron microscopy (TEM, Philips CM-10) and high resolution TEM (HRTEM, JEOL $2000 \mathrm{FX}$ ). The focused ion beam (FIB, FEI NOVA 660i) instrument was employed to cut the sample for cross-sectional morphology observation.

The detailed structural and compositional parameters of different $\mathrm{Si} / \mathrm{C}$ nanowire network electrodes tested in this study are listed in Table 1. The Si nanowire diameter and the thickness of carbon coating are measured using HRTEM images. To accurately measure the mass loading of the pure Si nanowire network, the mass $(M)$ of every sample with a size of $3.5 \times 6.5 \mathrm{~cm}^{2}$ had been weighed. The mass loading $\left(\rho_{A}\right)$ of pure $\mathrm{Si}$ nanowire network can be calculated as $\rho_{A}=\mathbf{M}$ / (3.5×6.5) $\mathrm{mg} \mathrm{cm}^{-2}$. The $\mathrm{Cu}$ layer content can be calculated by weighting the sample before and after evaporating the $200 \mathrm{~nm}$ Cu film. The carbon content of the electrode was then calculated by weighting the $\mathrm{Si} / \mathrm{C}$ nanowire networks before and after heating the sample in ambient environment at $600^{\circ}$ $\mathrm{C}$ for $1 \mathrm{~h}$, where the carbon can be burnt thoroughly and the color of sample changed from black to the original yellow color of the pure Si nanowire network [27]. There is negligible mass increase due to the oxidization of $\mathrm{Si}$ nanowires as we observed less than $0.5 \%$ weight difference in a reference pure

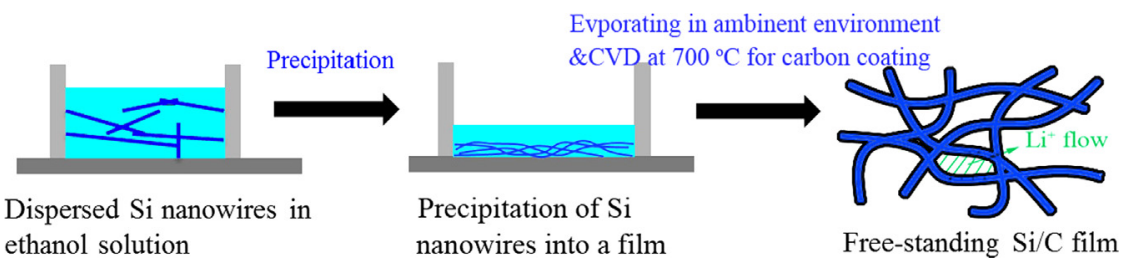

Fig. 1 Schematics of the fabrication process of Si/C nanowire network. 
Si nanowire network going through the same heating/burning process.

\section{Electrochemical measurements}

The free-standing $\mathrm{Si} / \mathrm{C}$ nanowire network electrodes were then punched into a 7/16 in. diameter disk and assembled into CR2032 coin cells with Li metal as counter electrodes and $1 \mathrm{M} \mathrm{LiPF}_{6}$ in ethylene carbonate (EC)/dimethyl carbonate (DMC) (1:1 volume ratio, Aldrich) as the electrolyte in an argon-filled glove box. Due to the intrinsic interconnections in the 3-D network structure, no binder material is used in this $\mathrm{Si} / \mathrm{C}$ nanowire network electrode. The $\mathrm{Si} / \mathrm{C}$ nanowire network using $\mathrm{Si}$ nanowires with the diameter of $75 \mathrm{~nm}$ is named as the "75 nm Si/C nanowire network" for short, and the one using Si nanowires with diameter of $37 \mathrm{~nm}$ is denoted as the "37 nm Si/C nanowire network". As a comparison, we also fabricated "milled $75 \mathrm{~nm} \mathrm{Si/C}$ nanowire electrode" using a process similar to the traditional electrode preparation process (See Supporting Information Section 2) [7]. The electrochemical performance was tested with a computer controlled battery testers (MTI, 5V1mA and 5V5mA) within the voltage windows of $0.01-2 \mathrm{~V}$ and $0.1-2 \mathrm{~V}$.

\section{Results and discussion}

Fig. 2a shows the optical image of one piece of $9 \times 9 \mathrm{~cm}^{2} \mathrm{Si}$ nanowire network consisting of $\mathrm{Si}$ nanowires with an average diameter of $75 \mathrm{~nm}$. Figs. $2 \mathrm{~b}$ and $\mathrm{c}$ show the top-view SEM image of the $75 \mathrm{~nm}$ Si nanowire network without and with CVD carbon coating. In both images, Si nanowires interweave with one another, with spontaneously formed micro/nano gaps at a

Table 1 Structural and compositional parameters of the tested $\mathrm{Si} / \mathrm{C}$ nanowire network electrodes consisted of Si nanowire network, carbon coating, and evaporated Cu layer.

\begin{tabular}{llllllll}
\hline$\#$ & $\begin{array}{l}\text { Si nanowire } \\
\text { diameters }(\mathrm{nm})\end{array}$ & $\begin{array}{l}\text { CVD } \\
\text { time }(\mathrm{h})\end{array}$ & $\begin{array}{l}\text { Carbon coating } \\
\text { thickness }(\mathrm{nm})\end{array}$ & $\begin{array}{l}\text { Carbon } \\
\text { content (\%) }\end{array}$ & $\begin{array}{l}\text { Cu layer } \\
\text { content (\%) }\end{array}$ & $\begin{array}{l}\text { Areal density } \\
\left(\mathrm{mg} \cdot \mathrm{cm}^{-2}\right)\end{array}$ & $\begin{array}{l}\text { Volumetric } \\
\text { density } \\
\left(\mathrm{g} \cdot \mathrm{cm}^{-3}\right)\end{array}$ \\
\hline 1 & 75 & 2 & $\sim 3$ & 4 & 8 & 1.34 & $\sim 0.27$ \\
2 & 75 & 4 & $\sim 6$ & 8 & 7 & 1.46 & $\sim 0.29$ \\
3 & 75 & 8 & $\sim 10$ & 12 & 7 & 1.52 & $\sim 0.3$ \\
4 & 37 & 8 & $\sim 10$ & 17 & 6 & 1.82 & $\sim 0.55$ \\
\hline
\end{tabular}
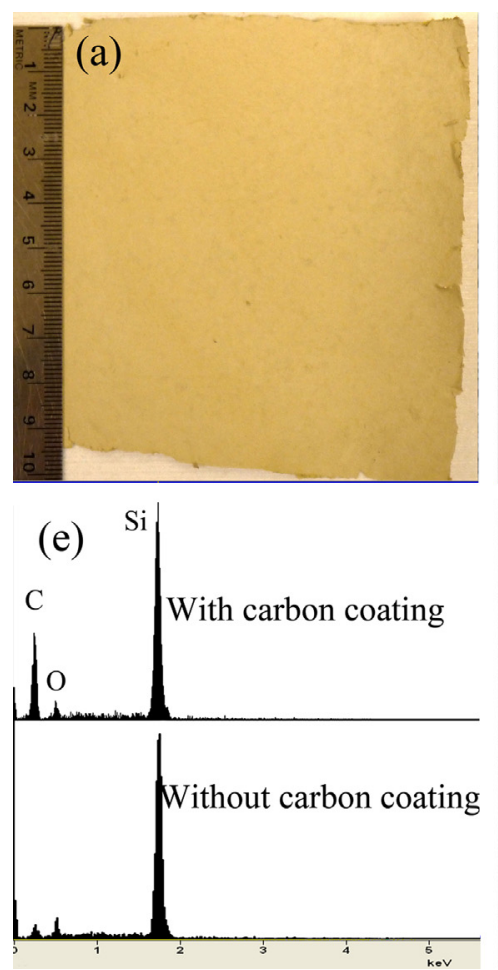
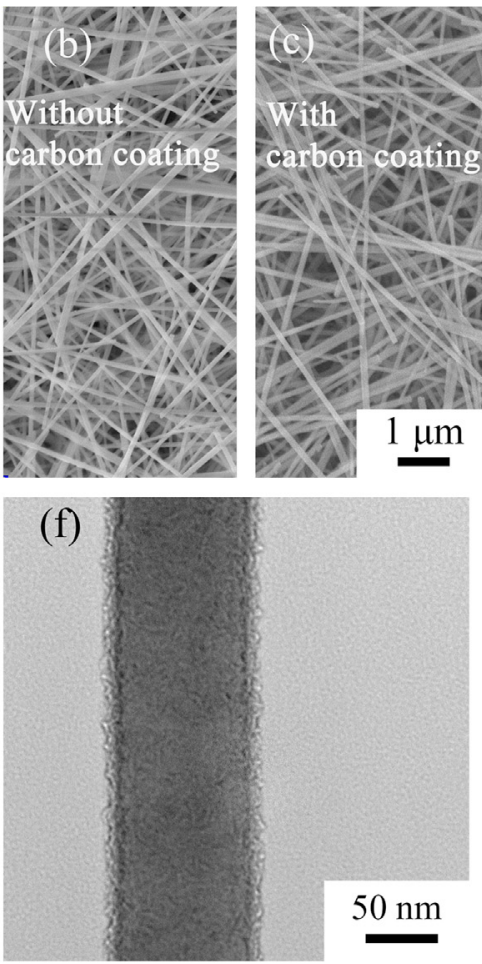
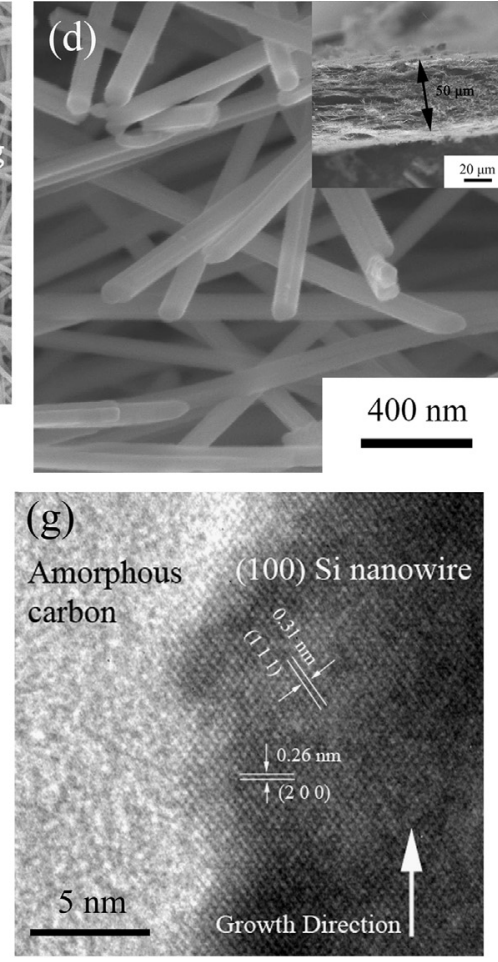

Fig. 2 (a) Optical image and (b) top-view FE-SEM image of a free-standing $75 \mathrm{~nm}$ Si nanowire network without carbon coating; (c) top-view FE-SEM image of the $75 \mathrm{~nm} \mathrm{Si/C} \mathrm{nanowire} \mathrm{network} \mathrm{with} 12 \mathrm{wt} \%$ carbon (the scale bar is same for both of (b) and (c)); (d) cross-sectional FE-SEM images of $75 \mathrm{~nm} \mathrm{Si/C}$ nanowire network with $12 \mathrm{wt} \%$ carbon after FIB milling process, the inset is the cross-sectional image of the $75 \mathrm{~nm} \mathrm{Si} / \mathrm{C}$ nanowire network; (e) EDS results of the $75 \mathrm{~nm}$ Si nanowire network without and with carbon coating, (f) TEM image of one individual $75 \mathrm{~nm} \mathrm{Si/C}$ core-shell nanowire and (g) HRTEM image of the Si-C interface. 
size range of tens of nanometers to a few micrometers. Fig. $2 d$ shows the cross-sectional FE-SEM image of the $75 \mathrm{~nm} \mathrm{Si/C}$ nanowire network with 8-h CVD carbon coating after FIB milling process. Apparently the nanoscale gaps are retained after the CVD coating process. The inset of Fig. $2 \mathrm{~d}$ shows that the sample thickness of the as-obtained $\mathrm{Si} / \mathrm{C}$ nanowire network is about $50 \mu \mathrm{m}$. The EDS results in Fig. 2e shows an increased carbon signal after 8-h CVD carbon coating. An individual $\mathrm{Si} / \mathrm{C}$ nanowire was characterized by the TEM after dispersing the sample in ethanol with ultrasonication for $20 \mathrm{~min}$. Fig. $2 \mathrm{f}$ shows a conformal carbon coating layer with a thickness of about $10 \mathrm{~nm}$ along the single $\mathrm{Si}$ nanowire. The silicon nanowire surface roughness originates from the wet etching process [28]. The HRTEM image in Fig. $2 \mathrm{~g}$ indicates that the $\mathrm{Si}$ nanowires is single crystalline and the carbon coating is amorphous. The fringe spacings show good agreement with the lattice spacings of (200) and (1111) planes as a cubic Si phase (JCPDS 80-0018), respectively. The result confirms that the $\left[\begin{array}{lll}1 & 0 & 0\end{array}\right]$ crystal orientation of the $\mathrm{Si}$ nanowires is the same as the original Si wafer orientation [29].

Fig. 3a compares the gravimetric discharge (lithiation) capacity of the $75 \mathrm{~nm} \mathrm{Si} \mathrm{nanowire} \mathrm{network} \mathrm{without} \mathrm{carbon}$ coating, the $\mathrm{Si} / \mathrm{C}$ nanowire network with $75 \mathrm{~nm}$ diameter $\mathrm{Si}$ nanowires and $12 \mathrm{wt} \%$ carbon coating, and the milled $75 \mathrm{~nm}$ $\mathrm{Si} / \mathrm{C}$ nanowire electrode. The $75 \mathrm{~nm} \mathrm{Si} / \mathrm{C}$ nanowire network and the milled $75 \mathrm{~nm} \mathrm{Si} / \mathrm{C}$ nanowire electrodes were tested at a current density of $0.4 \mathrm{~A} \mathrm{~g}^{-1}$ in the testing voltage window of $0.01-2 \mathrm{~V}$, while the $\mathrm{Si}$ nanowire network without carbon coating was tested at a lower current density of $0.12 \mathrm{Ag}^{-1}$ since it exhibited a negligible capacity at the current density of $0.4 \mathrm{Ag}^{-1}$ (see Supporting Information Section 3). A discharge capacity of $1800 \mathrm{mAh} \mathrm{g}^{-1}$ at the first cycle was observed for the $75 \mathrm{~nm}$ Si nanowire network without carbon coating, which, however, drops dramatically to almost zero in 6 cycles. The $75 \mathrm{~nm} \mathrm{Si} / \mathrm{C}$ nanowire network with $12 \mathrm{wt} \%$ carbon exhibits a higher discharge capacity of $2600 \mathrm{mAh} \mathrm{g}^{-1}$ at the first cycle, and, more importantly, a much better cycling stability. The discharge capacity is $2000-2300 \mathrm{mAh} \mathrm{g}^{-1}$ at the rate of $\mathrm{C} / 5$ in the next 20 cycles when a current of $0.4 \mathrm{~A} \mathrm{~g}^{-1}$ is applied $(C / n$ is referred as the charge/discharge rate to complete one charge/discharge cycle with full capacity $\boldsymbol{C}$ in $\boldsymbol{n}$ hours). The improvement in the 3-D Si/C nanowire network is attributed to the carbon coating, which has been widely used in various cathode and anode materials to improve the electrical conductivity and to provide the surface protection $[18,30]$. Besides that, the carbon coating in this 3-D Si nanowire network serves as the bonding layer to enhance the mechanical rigidity of the Si nanowire electrode. Fig. 3b shows the stress-strain behavior of the Si nanowire network with and without carbon coating. For each kind of samples, three specimens have been tested. The detailed experimental procedure is presented in the Supporting Information Section 4. The $75 \mathrm{~nm} \mathrm{Si} \mathrm{nanowire} \mathrm{networks} \mathrm{without}$ carbon coating were broken at failure strength of about 0.5 MPa. In contrast, the strength of the $\mathrm{Si} / \mathrm{C}$ nanowire network was greatly enhanced and it reaches $5 \mathrm{MPa}$, which was 10 times higher than that of the Si nanowire networks without carbon coating. In the pure Si nanowire network, the Si nanowires are simply next to each other without any intrinsic connection between the neighboring nanowires. After carbon coating, the carbon will wrap the nanowires and leads to the formation of interconnection between the $\mathrm{Si}$ nanowires. Thus, the mechanical strength can be greatly enhanced. The great enhancement of mechanical strength in $75 \mathrm{~nm} \mathrm{Si} / \mathrm{C}$ nanowire network with $12 \mathrm{wt} \%$ carbon suggests that the carbon coating could effectively strengthen the connections between Si nanowires in the network, and give rise to better mechanical stability of the electrode during electrochemical cycling.

On the other hand, a discharge capacity of $2200 \mathrm{mAh} \mathrm{g}^{-1}$ was delivered by the milled $75 \mathrm{~nm} \mathrm{Si} / \mathrm{C}$ nanowire electrode during the first cycle. However, it quickly drops to almost zero within 14 cycles. To understand the failure mechanism on the milled sample, the corresponding morphology was examined by FE-SEM, which indicates that the Si/C nanowires had been broken into short nanorods during the milling and mixing process (see Supporting Information Section 2). The connection between the Si nanowires was seriously destroyed although the silicon nanowire surfaces have been coated with CVD carbon. The PVDF binder materials and $A B$ carbon are not able to maintain the stable

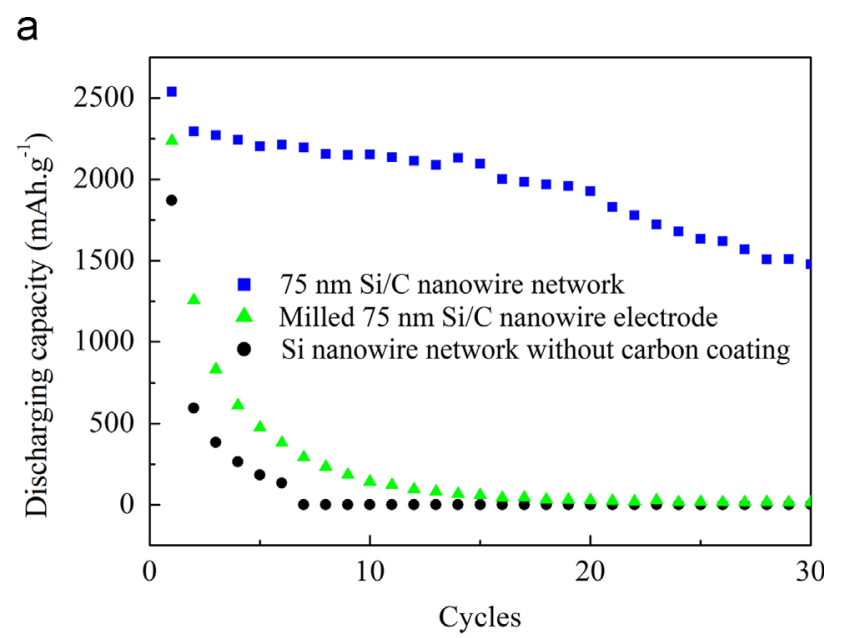

b

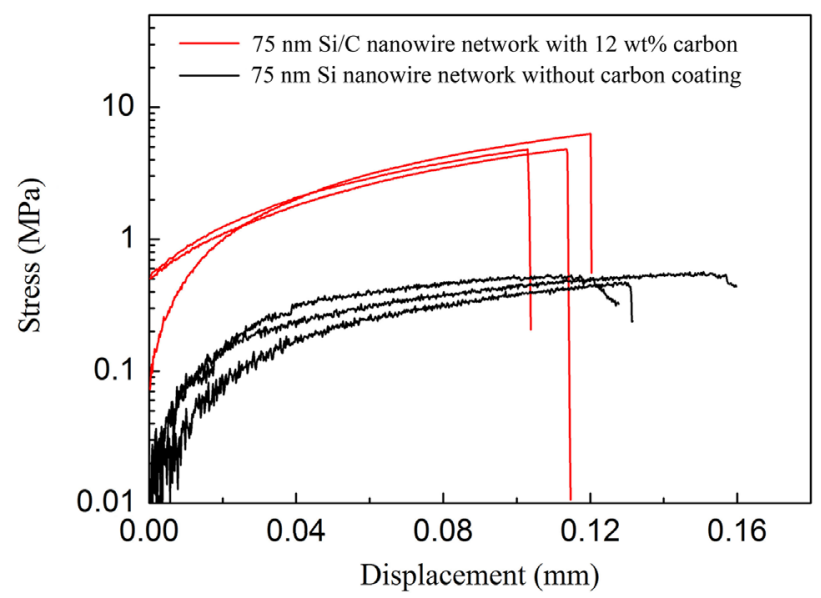

Fig. 3 (a) Gravimetric discharge capacity of the $75 \mathrm{~nm} \mathrm{Si}$ nanowire networks without carbon coating, the milled $75 \mathrm{~nm}$ $\mathrm{Si} / \mathrm{C}$ nanowire electrode and the $75 \mathrm{~nm} \mathrm{Si} / \mathrm{C}$ nanowire network with 12 wt\% carbon, tested at $0.4 \mathrm{~A} \mathrm{~g}^{-1}$; and (b) stress-displacement relations of the $75 \mathrm{~nm} \mathrm{Si} \mathrm{nanowire} \mathrm{network} \mathrm{without}$ carbon coating and the $75 \mathrm{~nm} \mathrm{Si} / \mathrm{C}$ nanowire network with $12 \mathrm{wt} \%$ carbon. 
electrical connection among Si nanostructures [31]. The lack of continuous electron transport pathways in the milled $\mathrm{Si} / \mathrm{C}$ nanowire electrode would unavoidably lead to capacity degradation.

We had also systematically studied the effect of carbon coating content on the galvanostatic cycling performance of the $\mathrm{Si} / \mathrm{C}$ nanowire networks. As shown in Fig. $4 \mathrm{a}$, all the $75 \mathrm{~nm}$ $\mathrm{Si} / \mathrm{C}$ nanowire network samples with carbon content of $4 \mathrm{wt} \%$, $8 \mathrm{wt} \%$ and $12 \mathrm{wt} \%$ after CVD carbon coating processes for 2 , 4 and $8 \mathrm{~h}$ exhibit high discharge capacity of over $2000 \mathrm{mAh} \mathrm{g}^{-1}$ for more than 10 cycles. The Coulombic efficiencies of these $\mathrm{Si} / \mathrm{C}$ nanowire networks at the first cycle are as high as $91 \%$ compared to the $60-80 \%$ in most other $\mathrm{Si}$ based electrodes $[7,32,33]$, and the Coulombic efficiencies increases to beyond $98 \%$ in later cycles. However, the discharge capacity degrades during cycling and drops in a faster rate after 10-20 cycles. There is an obvious transition point of the capacity degradation rate as the slope changes in all three curves. When the carbon content is increased from $4 \mathrm{wt} \%$ to $12 \mathrm{wt} \%$, the transition point of the capacity degradation rate is delayed

\section{a}

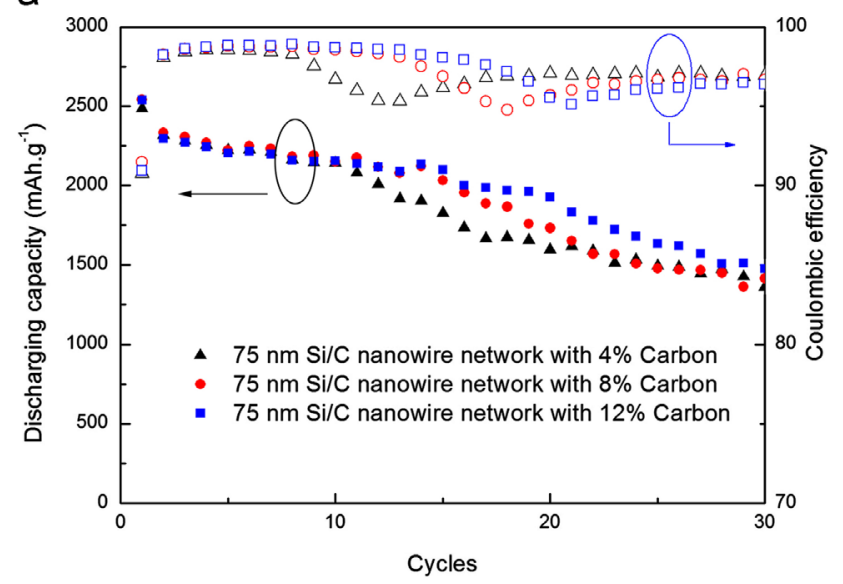

b

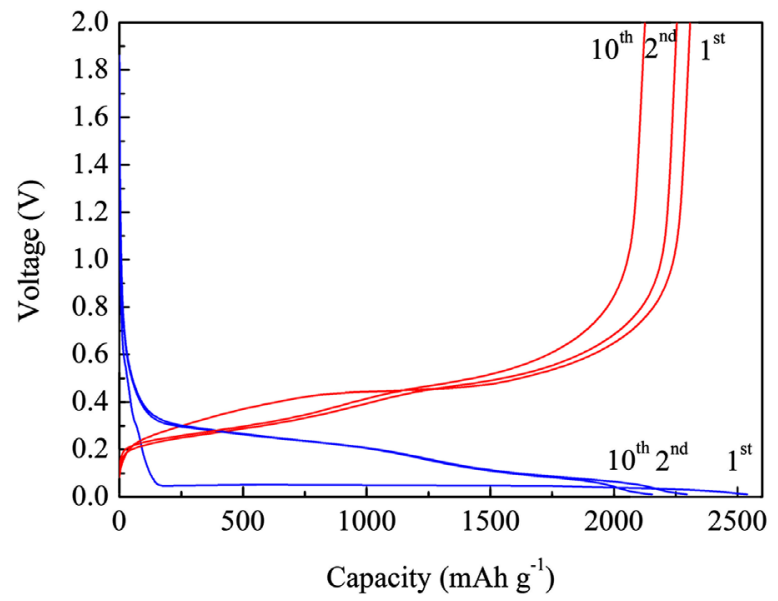

Fig. 4 (a) Gravimetric discharge capacity of $75 \mathrm{~nm} \mathrm{Si/C}$ nanowire network with different carbon coatings tested at $0.4 \mathrm{~A} \mathrm{~g}^{-1}$ and the corresponding Coulombic efficiencies (to the right axis), and (b) galvanostatic discharge/charge curves of $75 \mathrm{~nm} \mathrm{Si} / \mathrm{C}$ nanowire network with $12 \mathrm{wt} \%$ carbon tested at $0.4 \mathrm{~A} \mathrm{~g}^{-1}$. from the 13th to the 21st cycle. This indicates that thicker carbon coating can provide a more stable structure for better cycling performance. Fig. 4b shows the galvanostatic discharge/charge curves of the $75 \mathrm{~nm} \mathrm{Si} / \mathrm{C}$ nanowire network with $12 \mathrm{wt} \%$ carbon. It shows a large irreversible discharge capacity at the first cycle with a plateau at around $0.05 \mathrm{~V}$, which is consistent with other results of single crystalline $\mathrm{Si}$ $[10,34]$. The large irreversible capacity at the first cycle is due to the irreversible transition from crystalline $\mathrm{Si}$ to amorphous $\mathrm{Li}_{x} \mathrm{Si}$ and also the formation of SEl layer [33,35]. After the second cycle, it exhibits the typical electrochemical behavior of $\mathrm{Li}_{x} \mathrm{Si}$ with a flat reversible discharge voltage plateau in the range of $0.2-0.6 \mathrm{~V}$ and a charge voltage plateau in the range of $0.01-0.4 \mathrm{~V}[10,36]$.

Fig. 5 shows that the anode performance of the $\mathrm{Si} / \mathrm{C}$ nanowire networks can be improved by reducing the diameters of $\mathrm{Si}$ nanowires and the testing voltage windows. All the tested samples were CVD-coated with carbon for $8 \mathrm{~h}$. When the nanowire diameter decreases from $75 \mathrm{~nm}$ to $37 \mathrm{~nm}$, the discharge capacity decreases slightly to around $1700 \mathrm{mAh}$ $\mathrm{g}^{-1}$ which might be due to the higher weight percentage of carbon (17 wt\% comparing to $12 \mathrm{wt} \%$ ) and a little higher $C$-rate $(C / 4$ comparing to $C / 6)$. However, the stability is improved greatly in $37 \mathrm{~nm} \mathrm{Si} / \mathrm{C}$ nanowire network with $17 \mathrm{wt} \%$ carbon. The transition point of discharge capacity degradation rate changes to the 30th cycle compared to the 21st cycle in $75 \mathrm{~nm} \mathrm{Si} / \mathrm{C}$ nanowire network with $12 \mathrm{wt} \%$ carbon. On the other hand, the structural stability can also be improved by reducing the testing voltage window which reduces the amount of Li ions inserted. Due to the low initial discharge plateau at about 0.03-0.05 V shown in Fig. 4b, Si/C nanowire networks were tested in the voltage window of $0.01-2 \mathrm{~V}$ for the first cycle to activate the lithiation of crystalline $\mathrm{Si}$ nanowires. The testing voltage window was changed after the first cycle to $0.1-2 \mathrm{~V}$. Starting from the fifth cycle, the discharge capacity turns to be stable around $1200 \mathrm{mAh} \mathrm{g}^{-1}$ for $75 \mathrm{~nm} \mathrm{Si} / \mathrm{C}$ nanowire network with $12 \mathrm{wt} \%$ carbon and around $1000 \mathrm{mAh} \mathrm{g}^{-1}$ for the $37 \mathrm{~nm} \mathrm{Si} / \mathrm{C}$ nanowire network with $17 \mathrm{wt}$ $\%$ carbon. Meanwhile, the cycle life is greatly improved by reducing the voltage window. Fig. $5 \mathrm{~b}$ presents the discharge capacity normalized by the discharge capacity at the fifth cycle. The $37 \mathrm{~nm} \mathrm{Si} / \mathrm{C}$ nanowire network with $17 \mathrm{wt} \%$ carbon retains $78 \%$ of the initial capacity over 60 cycles in the voltage window of $0.1-2 \mathrm{~V}$ compared to $40 \%$ in the voltage window of 0.01-2 V.

Fig. 6 shows the rate capability of $\mathrm{Si} / \mathrm{C}$ nanowire network anodes with Si nanowire diameters of $75 \mathrm{~nm}$ and $37 \mathrm{~nm}$, both with 8-h CVD carbon coating and tested in the charge/ discharge testing window of 0.01-2 V. For both of samples tested, the testing current density was doubled every four cycles with the initial current density of $0.2 \mathrm{~A} \mathrm{~g}^{-1}$. At the low current density of $0.2 \mathrm{~A} \mathrm{~g}^{-1}$, the discharge capacity can reach $2500 \mathrm{mAh} \mathrm{g}^{-1}$ for the $75 \mathrm{~nm} \mathrm{Si/C}$ nanowire network and $1800 \mathrm{mAh} \mathrm{g}^{-1}$ for the $37 \mathrm{~nm} \mathrm{Si} / \mathrm{C}$ nanowire network. While the current density is increased to be $3.2 \mathrm{~A} \mathrm{~g}^{-1}$, the discharge capacity remains $25 \%$ of the initial discharge capacity for both of the samples, as shown in the inset of Fig. 6. It is worthwhile to mention that a high discharge capacity of $600 \mathrm{mAh} \mathrm{g}^{-1}$ at a high rate of $4.5 \mathrm{C}$ is observed for the $75 \mathrm{~nm} \mathrm{Si} / \mathrm{C}$ nanowire network with $12 \mathrm{wt} \%$ carbon, which is larger than the theoretical capacity of commercial graphite $\left(372 \mathrm{mAh} \mathrm{g}^{-1}\right)$ and 5 times higher than that of annealed graphite at the 
a

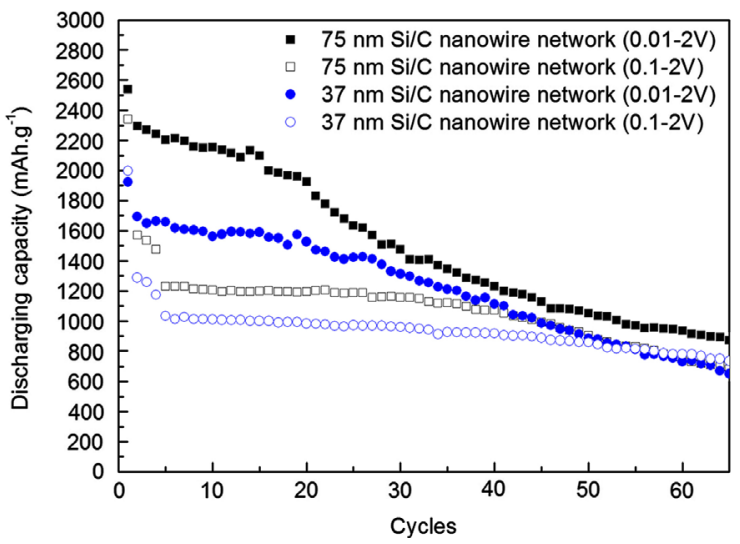

b

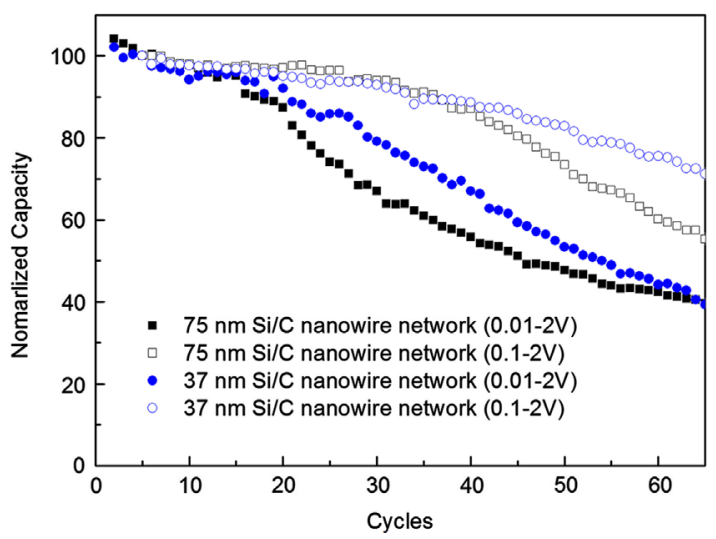

Fig. 5 (a) Gravimetric discharge capacity and (b) normalized discharge capacity, of $75 \mathrm{~nm} \mathrm{Si} / \mathrm{C}$ nanowire network with 12 wt\% carbon and $37 \mathrm{~nm} \mathrm{Si/C}$ nanowire network with $17 \mathrm{wt} \%$ carbon tested at different testing voltage windows.

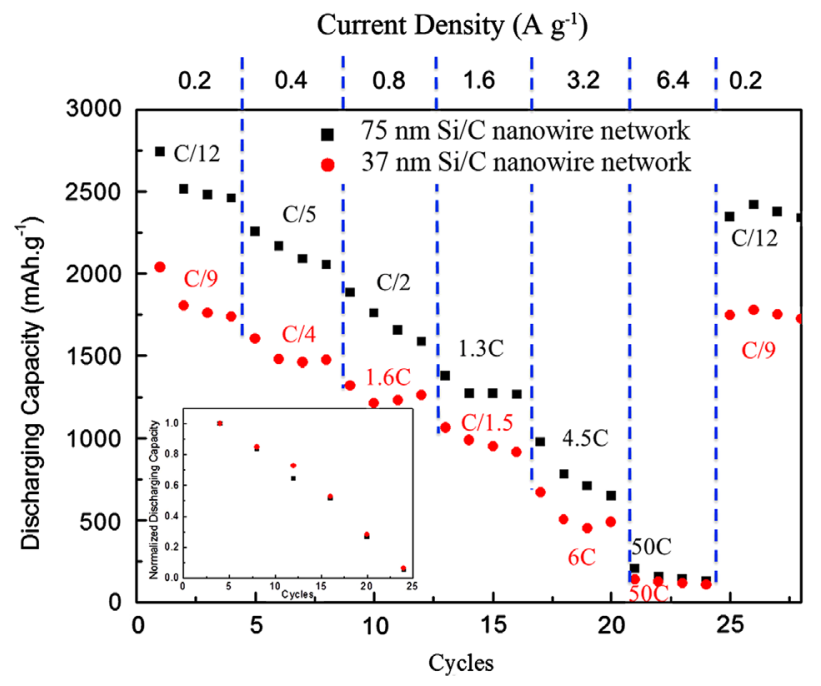

Fig. 6 Rate capabilities of the $75 \mathrm{~nm} \mathrm{Si} / \mathrm{C}$ nanowire network electrode with $12 \mathrm{wt} \%$ carbon (black square) and the $37 \mathrm{~nm} \mathrm{Si} / \mathrm{C}$ nanowire network electrode with 17 wt\% carbon (red circle); the discharge capacity of last cycle in every four cycle is normalized by the discharge capacity at the fourth cycle, and the inset is the normalized capacities vs. cycles. (For interpretation of the references to color in this figure legend, the reader is referred to the web version of this article.)

same rate [37]. It is a little higher than that of the 3-D inverseopal Si networks and comparable to that of the 3-D Ni/Si bicontinuous networks based on $500 \mathrm{~nm}$ colloid template, which both form 3-D porous electrodes for Li-ion penetration $[18,19]$. One would expect a better rate capability for the smaller nanowires with shorter Li ion diffusion length. However, the rate capabilities for $\mathrm{Si} / \mathrm{C}$ nanowire network with diameters of both $75 \mathrm{~nm}$ and $37 \mathrm{~nm}$ are quite close to each other, as shown in inset of Fig. 6, which is likely due to the density difference of the samples. As seen in Table 1, the volumetric density of the $37 \mathrm{~nm} \mathrm{Si} / \mathrm{C}$ nanowire network with 17 wt\% is $0.55 \mathrm{~g} \mathrm{~cm}^{-3}$, which is much higher than that of the $75 \mathrm{~nm} \mathrm{Si} / \mathrm{C}$ nanowire network with $12 \mathrm{wt} \%$ carbon, $\sim 0.3 \mathrm{~g}$ $\mathrm{cm}^{-3}$. Higher density results in less empty space for both Li-ion flow and volume exchange accommodation [38].
To understand the failure mechanism of the $\mathrm{Si} / \mathrm{C}$ nanowire network in Li-ion batteries, the $75 \mathrm{~nm} \mathrm{Si} / \mathrm{C}$ nanowire network with 12 wt\% carbon after testing for 70 cycles with a testing current density of $0.4 \mathrm{~A} \mathrm{~g}^{-1}$ was cleaned with DMC solution in a glove box, and then examined by FE-SEM and TEM, as shown in Fig. $7 a$ and $b$. The nanowires are significantly bended compared to the straight and smooth nanowires before cycling in Fig. 2b. Compared to the $75 \mathrm{~nm}$ dense Si nanowire with clear carbon coating in thickness of $10 \mathrm{~nm}$ on surface, the Si/C coreshell nanowire becomes porous with a expanded diameter of $140-150 \mathrm{~nm}$. The morphorgies are consistent with other reports because the huge volume expansion of $>300 \%$ can lead to the structure expansion of $160 \%$ in the axial and radius directions, respectively $[6,39]$. Nanopores can be gradually genernated during the cycling process, which has been demonstrated in $\mathrm{ZnO}$ and Si nanowires [40]. Such volume expansion could result in the capacity degradation through two possible mechanisms: (1) it leads to the pulverization in Si nanowires [6]. However, as demonstrated in Fig. 7a, the Si nanowires continuous with a bended morphology and do not break into short nanorods or nanoparticles. Both of the theoretical and experimental works have demonstrated that the $\mathrm{Si}$ nanostructures with dimensions smaller than $150 \mathrm{~nm}$ are able to survive during the structure expansion $[6,41,42]$. (2)Very likely, it breaks the connection between active $\mathrm{Si}$ and conducting materials $[43,44]$. As schemed in Fig. $7 c$, the lithiation process results in the structure expansion both in radius direction and along the nanowire. The volume expansion in the radius direction will break the interconnection due to the large volume expansion mismatch between the active $\mathrm{Si}(>300 \%)$ and the conducting carbon layer (9\%) [35]. The volume expansion along the nanowire would lead to the bending of nanowires and thus a stress is generated at the interface between Si nanowires. The repeating expanding and shrinking will make the interconnections loose. Once it reaches the fatigue strength of the carbon bonding layer, the Si nanowires will lose the connection to the electrode system, and cannot contribute to the capacity and thus results in the capacity degradation of electrode. Thus, the transition point of the capacity degradation rate appeared. It is consistent with our results that the pure $\mathrm{Si}$ nanowire network without carbon coating exhibits rapid capacity degradation, and the more carbon coating can provide stronger bonding strength and hence longer cycle life. 


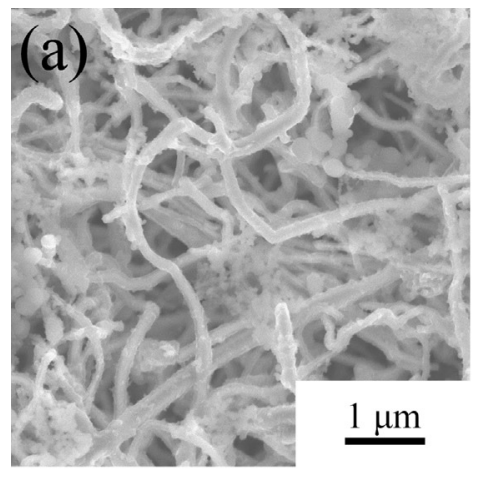

(c)
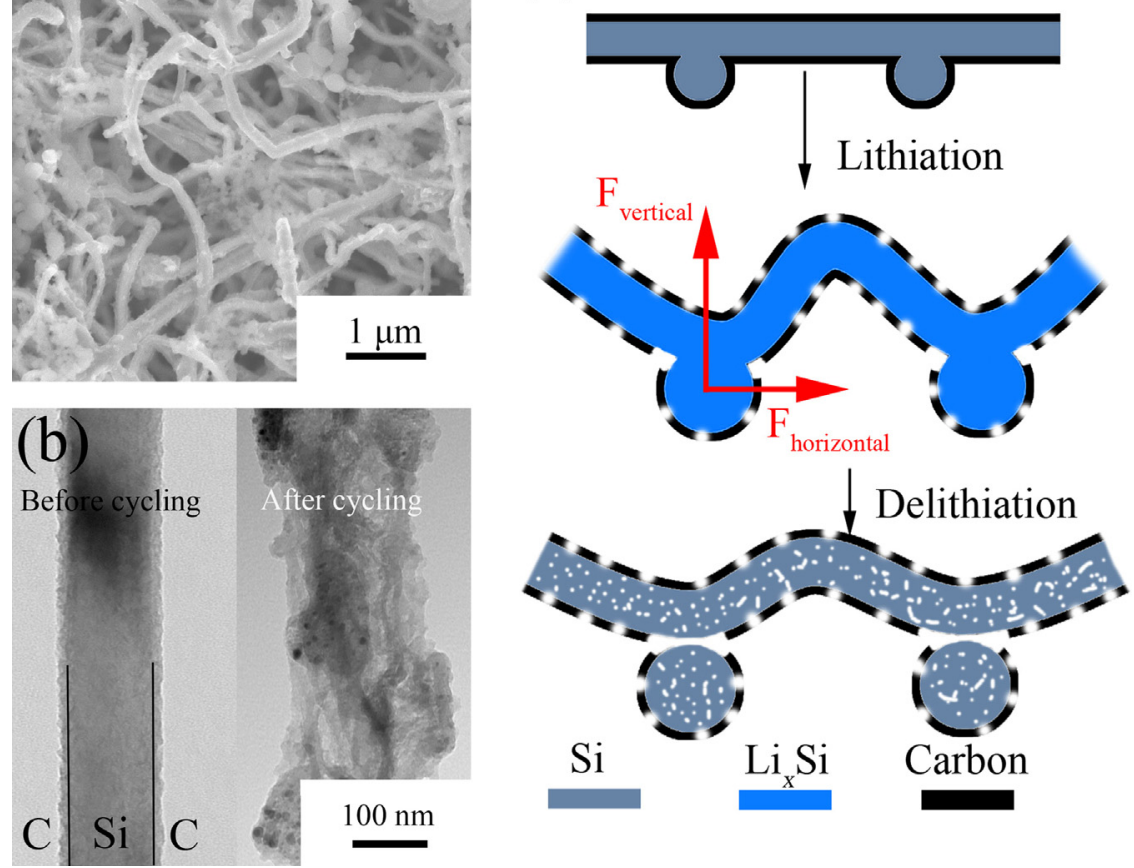

Fig. 7 (a) Top-view FE-SEM image of $75 \mathrm{~nm} \mathrm{Si/C}$ nanowire network with $12 \mathrm{wt} \%$ carbon after testing for 70 cycles at a testing current of $0.4 \mathrm{~A} \mathrm{~g}^{-1}$; (b) TEM image of $\mathrm{Si} / \mathrm{C}$ nanowire before and after testing for 70 cycles; and (c) schematics of possible failure mechanism on the $\mathrm{Si} / \mathrm{C}$ nanowire network.

\section{Conclusions}

We have successfully fabricated the 3-D $\mathrm{Si} / \mathrm{C}$ nanowire networks by CVD carbon coating on facile-precipitated $\mathrm{Si}$ nanowire network. Si nanowires are connected to one another with spontaneous formation of micro/nano gaps, which is beneficial for Li-ion flow and volume expansion accommodation. In the $75 \mathrm{~nm} \mathrm{Si} / \mathrm{C}$ nanowire network with $12 \mathrm{wt} \%$ carbon, a very high discharge capacity of $2300 \mathrm{mAh}$ $\mathrm{g}^{-1}$ at a rate of $C / 5$ has been achieved, and a high capacity of about $600 \mathrm{mAh} \mathrm{g}^{-1}$ is reached at a very high discharge rate of $4.5 \mathrm{C}$. The cycle life can be increased by increasing the carbon coating content with a stronger bonding strength, decreasing the diameters of Si nanowires, and reducing the testing voltage window to alleviate volume expansion.

\section{Acknowledgment}

This work is supported by the DARPA Center on Nanoscale Science and Technology for Integrated Micro/Nano-Electromechanical Transducers (iMINT), supported by the Defense Advanced Research Projects Agency (DARPA) N/ MEMS S\&T Fundamentals program under Grant no. N66001-10-1-4007 issued by the Space and Naval Warfare Systems Center Pacific (SPAWAR). Some of the micro/ nano-fabrication work was conducted in the Colorado Nanofabrication Laboratories, supported in part by the NNIN and the National Science Foundation under Grant no. ECS-0335765.

\section{Appendix A. Supporting information}

Supplementary data associated with this article can be found in the online version at: http://dx.doi.org/10.1016/ j.nanoen.2013.03.015.

\section{References}

[1] C. Liu, F. Li, L.P. Ma, H.M. Cheng, Advanced Materials 22 (2010) E28.

[2] R.F. Nelson, Journal of Power Sources 91 (2000) 2.

[3] M. Armand, J.-M. Tarascon, Nature 451 (2008) 652.

[4] Y. He, X.Q. Yu, Y.H. Wang, H. Li, X.J. Huang, Advanced Materials 23 (2011) 4938.

[5] U. Kasavajjula, C.S. Wang, A.J. Appleby, Journal of Power Sources 163 (2007) 1003.

[6] C.K. Chan, H.L. Peng, G. Liu, K. Mcllwrath, X.F. Zhang, R.A. Huggins, Y. Cui, Nature Nanotechnology 3 (2008) 31.

[7] H.J. Kim, M.H. Seo, M.H. Park, J.P. Cho, Angewandte Chemie International Edition 49 (2010) 2146.

[8] C.K. Chan, R.N. Patel, M.J. O'Connell, B.A. Korgel, Y. Cui, ACS Nano 3 (2010) 1443.

[9] M.H. Park, M.G. Kim, J. Joo, K. Kim, J. Kim, S. Ahn, Y. Cui, J. Cho, Nano Letters 9 (2009) 3844.

[10] L.F. Cui, R. Ruffo, C.K. Chan, H.L. Peng, Y. Cui, Nano Letters 9 (2009) 491.

[11] L.F. Cui, Y. Yang, C.M. Hsu, Y. Cui, Nano Letters 9 (2009) 3370.

[12] M. Tian, W. Wang, Y.J. Wei, R.G. Yang, Journal of Power Sources 211 (2012) 46.

[13] W. Wang, M. Tian, A. Abdulagatov, S.M. George, Y.-C. Lee, R.G. Yang, Nano Letters 12 (2011) 655. 
[14] M. Rauber, I. Alber, S. Müller, R. Neumann, O. Picht, C. Roth, A. Schokel, M.E. Toimil-Molares, W. Ensinger, Nano Letters 11 (2011) 2304.

[15] H.G. Zhang, X.D. Yu, P.V. Braun, Nature Nanotechnology 6 (2011) 277.

[16] H.T. Nguyen, F. Yao, M.R. Zamfir, C. Biswas, K.P. So, Y.H. Lee, S.M. Kim, S.N. Cha, J.M. Kim, D. Pribat, Advanced Energy Materials 1 (2011) 1154.

[17] Y. Yao, M.T. McDowell, I. Ryu, H. Wu, N. Liu, L.B. Hu, W.D. Nix, Y. Cui, Nano Letters 11 (2011) 2949.

[18] A. Esmanski, G.A. Ozin, Advanced Functional Materials 19 (2009) 1999.

[19] H.G. Zhang, P.V. Braun, Nano Letters 12 (2012) 2778.

[20] W. Wang, D. Li, M. Tian, Y.C. Lee, R.G. Yang, Applied Surface Science 258 (2012) 8649.

[21] M.S. Gudiksen, C.M. Lieber, Journal of the American Chemical Society $122(2000) 8801$.

[22] D.P. Yu, Z.G. Bai, Y. Ding, Q.L. Hang, H.Z. Zhang, J.J. Wang, Y.H. Zou, W. Qian, G.C. Xiong, H.T. Zhou, S.Q. Feng, Applied Physics Letters 72 (1998) 3458.

[23] J. Mallet, M. Molinari, F. Martineau, F. Delavoie, P. Fricoteaux, M. Troyon, Nano Letters 8 (2008) 3468.

[24] Z.P. Huang, N. Geyer, P. Werner, J. de Boor, U. Gösele, Advanced Materials 23 (2011) 285.

[25] C. Chiappini, X.W. Liu, J.R. Fakhoury, M. Ferrari, Advanced Functional Materials 20 (2010) 2231.

[26] M.L. Zhang, K.Q. Peng, X. Fan, J.S. Jie, R.Q. Zhang, S.T. Lee, N. B. Wong, The Journal of Physical Chemistry C 112 (2008) 4444.

[27] H. Wu, G. Chan, J.W. Choi, I. Ryu, Y. Yao, M.T. McDowell, S.W. Lee, A. Jackson, Y. Yang, L.B. Wu, Y. Cui, Nature Nanotechnology 7 (2012) 309.

[28] A.I. Hochbaum, R.K. Chen, R.D. Delgado, W.J. Liang, E.C. Garnett, M. Najarian, A. Majumdar, P.D. Yang, Nature 451 (2008) 163.

[29] K.Q. Peng, Y.J. Yan, S.P. Gao, J. Zhu, Advanced Materials 14 (2002) 1164.

[30] Y. Zhang, Q.Y. Huo, P.P. Du, L.Z. Wang, A.Q. Zhang, Y.H. Song, Y. Lv, G.Y. Li, Synthetic Metals 162 (2012) 1315.

[31] I. Kovalenko, B. Zdyrko, A. Magasinski, B. Hertzberg, Z. Milicev, R. Burtovyy, I. Luzinov, G. Yushin, Science 334 (2011) 75 .

[32] P.F. Gao, H.P. Jia, J. Yang, Y.N. Nuli, J.L. Wang, J. Chen, Physical Chemistry Chemical Physics 13 (2011) 20108.

[33] X.J. Feng, J. Yang, P.F. Gao, J.L. Wang, Y.N. Nuli, RSC Advances 2 (2012) 5701.

[34] M.N. Obrovac, L.J. Krause, Journal of the Electrochemical Society 154 (2007) A103.

[35] S.C. Zhang, Z.J. Du, R.X. Lin, T. Jiang, G.R. Liu, X.M. Wu, D.S. Weng, Advanced Materials 22 (2010) 5378.

[36] L.F. Cui, L.B. Hu, J.W. Choi, Y. Cui, ACS Nano 4 (2010) 3671.

[37] A. Magasinski, P. Dixon, B. Hertzberg, A. Kvit, J. Ayala, G. Yushin, Nature Materials 9 (2010) 353.

[38] W. Lai, C.K. Erdonmez, T.F. Marinis, C.K. Bjune, N.J. Dudney, F. Xu, R. Wartena, Y.M. Chiang, Advanced Materials 22 (2010) E139.

[39] X.H. Liu, L.Q. Zhang, L. Zhong, Y. Liu, H. Zheng, J.W. Wang, J.H. Cho, S.A. Dayeh, S.T. Picraux, J.P. Sullivan, S.X. Mao, Z.Z. Ye, J.Y. Huang, Nano Letters 11 (2011) 2251-2258.

[40] J.W. Choi, J. McDonough, S. Jeong, J.S. Yoo, C.K. Chan, Y. Cui, Nano Letters 10 (2010) 1409-1413.

[41] X.H. Liu, L. Zhong, S. huang, S.X. Mao, T. Zhu, J.Y. Huang, ACS Nano 2 (2012) 1522-1531.

[42] S. Golmon, K. Maute, S.H. Lee, M.L. Dunn, Applied Physics Letters 97 (2010) 033111.

[43] C.J. Yu, X. Li, T. Ma, J.P. Rong, R.J. Zhang, J. Shaffer, Y.H. An, Q. Liu, B.Q. Wei, H.Q. Jiang, Advanced Energy Materials 2 (2012) 68-73.

[44] J.P. Maranchi, A.F. Hepp, A.G. Evans, N.T. Nuhfer, P.N. Kumta, Journal of the Electrochemical Society 153 (2006) A1246-A1253.

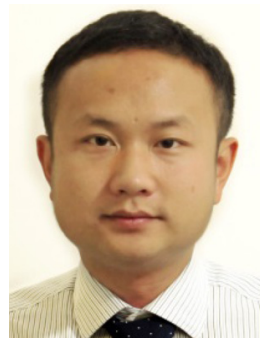

Wei Wang received his BS in Materials Physics (2003) and PhD in Condensed Matter Physics (2008) from University of Science and Technology of China, and he is a post-doctor in Department of Mechanical Engineering at University of Colorado - Boulder. His current research focuses on micro/nano-manufacturing of three-dimensional architectures for energy harvesting and storage applications.

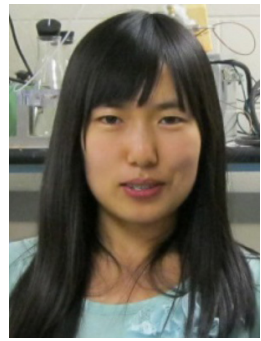

Miao Tian is now a graduate student in Departmert of Mechanical Engineering at University of Colorado - Boulder. She received her BS degree from Xi'an Jiaotong University in 2007. Her current research foucuses on fabrication of three-dimensional nanostructures for Lithium-ion battery applications.

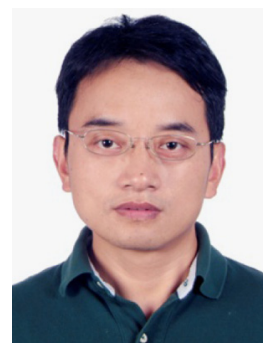

Yujie Wei is now a Professor at Institute of Mechanics, Chinese Academy of Sciences. He receiced his BS degree in Mechanics from Beijing University in 1997, and earned his $\mathrm{PhD}$ degree in Applied Mechanics from Massachusetts Institute of Technology in 2006. His research focuses on mechanics of materials.

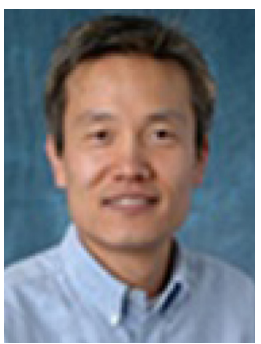

Se-hee Lee is an Associate Professor in Department of Mechanical Engineering at University of Colorado - Boulder. He receiced his BS degree (1991) in Metallurgical Engineering and earned his PhD degree (1997) in Materials Science and Engineering from Seoul National University. His primary research interests have concentrated on nanostructured materials for energy applications.

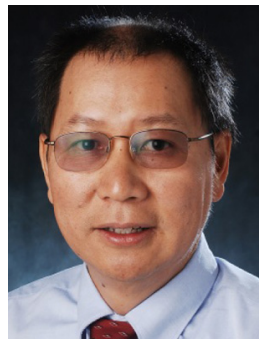

Yung-Cheng (YC) Lee received his BSME degree from the National Taiwan University in 1978, and the M.S. and Ph.D. degrees from the University of Minnesota, in 1982 and 1984, respectively. Y. C. Lee is S.J. Archuleta Professor of Mechanical Engineering and the Director of DARPA Center on Nanoscale Science and Technology for Integrated Micro/Nano-Electromechanical Transducers (iMINT) at the University of Colorado-Boulder. Dr. Lee's research focuses on the integration of microelectromechanical systems (MEMS) and nanoelectromechanical systems (NEMS) with microelectronic, optoelectronic and microwave devices.

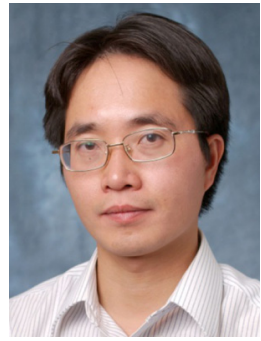

Ronggui Yang (Ph.D MIT 2006, MS MEMS-UCLA 2001, MS Thermophysics -Tsinghua 1999, BS Thermal Engineering-Xi'an Jiaotong Univ 1996) is an Assocaite Professor of Mechanical Engineering at the University of Colorado - Boulder. His research interests are on the fundamentals of nanoscale transport phenomena and the applications of micro/nanotechnologies for energy conversion, storage and thermal. 